\title{
Magnitude estimation of warmth: Intra- and intersubject variability
}

\author{
ROBERTO REFINETTI \\ University of California, Santa Barbara, California
}

\begin{abstract}
Fifty-two subjects, both male and female, 18 to 62 years old, were asked to hold a metal bar maintained at different temperatures $\left(33^{\circ}\right.$ to $\left.42^{\circ} \mathrm{C}\right)$, and to estimate the magnitude of the resulting thermal sensation. On the average, the estimates were linearly related to the stimulus temperature, although most individual subjects either under- or overestimated middle-range values. Intersubject variability, which was twice as large as intrasubject variability, could not be accounted for by gender, age, or body-temperature differences.
\end{abstract}

The dynamics of thermal sensations have been studied for several decades (for reviews, see Hensel, 1981; J. C. Stevens, 1983). In particular, the magnitude of warmth sensation has been shown to depend on stimulus magnitude (Herget, Granath, \& Hardy, 1941; J. C. Stevens \& S. S. Stevens, 1960), stimulus location (J. C. Stevens, Marks, \& Simonson, 1974), stimulus size (J. C. Stevens \& Marks, 1971; Marks, J. C. Stevens, \& Tepper, 1976), stimulus duration (Marks \& J. C. Stevens, 1973a, 1973b), and state of adaptation (Kenshalo \& Scott, 1966; Molinari, Greenspan, \& Kenshalo, 1977). As in other sensory modalities, estimates of warmth $(E)$ are believed to be related to stimulus magnitude $(S)$ according to a power function: $E=k S^{\beta}$.

The problem of variability in tasks of magnitude estimation and cross-modality matching has received considerable attention in the psychophysical literature. The exponent $\beta$ has been shown to vary in at least three situations: (1) when the same type of response is used for judgments about different sensory modalities (Ekman, Hosman, Lindman, Ljungberg, \& Ákesson, 1968; Jones \& Marcus, 1961; Jones \& Woskow, 1962; Rule, 1966; S. S. Stevens, 1966); (2) when the same sensory modality is judged according to different types of response (Engeland \& Dawson, 1974; Hellman, 1981; Rule \& Markley, 1971; J. C. Stevens \& Marks, 1967; R. Teghtsoonian \& M. Teghtsoonian, 1978); and (3) when the same subjects are tested in the same sensory modality and on the same type of response on different occasions (Da Silva \& Fukusima, 1986; Hellman, 1981; Logue, 1976; M. Teghtsoonian \& R. Teghtsoonian, 1971, 1983). The present study is concerned with the third situation (intrasubject variability) as well as with a fourth onenamely, that in which different subjects are tested in the

This research was conducted while the author was a faculty member at the Institute of Psychology, University of São Paulo, 05508 São Paulo, Brazil. Thanks are due Jack Loomis, Martha Teghtsoonian, and Lawrence Marks for comments on an earlier draft of the paper. The author's current address (to which requests for reprints should be sent) is: Department of Psychology, University of Illinois, Champaign, IL 61820 . same sensory modality and with the same type of response (intersubject variability). The extent of intra- and intersubject variability in magnitude estimation of warmth was investigated in a relatively large sample of male and female subjects of different ages.

\section{METHOD}

The subjects were 52 volunteers of both sexes, ranging in age from 18 to 60 years. All sessions were conducted in a thermostatically controlled room set to $25^{\circ} \mathrm{C}$. The thermal stimulator consisted of a thin-wall brass tube (26 $\mathrm{mm}$ in diameter, $15 \mathrm{~cm}$ long) perfused with water at different temperatures and housed in a Plexiglas frame placed on top of a table in the center of the room. Water maintained at $22^{\circ} \mathrm{C}$ passed through a heat exchanger immersed in a $50^{\circ} \mathrm{C}$ water bath and then perfused the stimulator, whose temperature was varied by varying the flow rate in the system. A miniature thermocouple (Sensortek IT-23) was attached to the surface of the stimulator and connected to a thermocouple meter (Sensortek BAT-12).

Upon their arrival in the laboratory, the subjects were taken to the experimental room and asked to sit quietly for $10 \mathrm{~min}$. At the end of this period, measurements were made of sublingual temperature and heart rate. The subjects were then instructed to (1) wait for a verbal signal, (2) place the right hand on the stimulator and hold it only for long enough to have a clear thermal sensation, and (3) remove the hand and report the sensation. Thirty stimuli were presented per session at approximately 40 -sec intervals, in accordance with the method of constant stimuli (Graham, 1950). In order to prevent any distortions in the power function exponent due to a short stimulus range (see $R$. Teghtsoonian, 1971), the temperature was varied from $33.2^{\circ}$ to $42.4^{\circ} \mathrm{C}$, which covered almost the whole range of nonnoxious warmth sensations (the approximate warmth and pain thresholds for these subjects were $33^{\circ}$ and $45^{\circ} \mathrm{C}$, respectively).

The duration of each stimulus depended to a certain extent on the subject's response, but each subject was initially instructed to hold the stimulator for not less than $3 \mathrm{sec}$ and not more than $7 \mathrm{sec}$, which is a duration long enough to prevent problems due to temporal summation (Marks \& J. C. Stevens, 1973b) but short enough to prevent complications due to sensory adaptation (Kenshalo \& Scott, 1966). The effective area of stimulation on the palm of the hand was approximately $50 \mathrm{~cm}^{2}$.

Seven subjects were tested three times on different days. The remaining $\mathbf{4 5}$ subjects were tested only once. In the first session for each subject (or the only session for those who were tested only once), the series of 30 stimuli was preceded by a training phase. 
First, a stimulus of approximately $33^{\circ} \mathrm{C}$ was presented, and the subject was instructed to call it a " $20^{\prime}$ " sensation. Then, 3 to 7 other stimuli were presented, and the subject was asked to estimate their magnitudes. When it was evident that the subject had understood the task, data collection was initiated. Subjects tested more than once were always given a reference stimulus (magnitude " 20 ") at the beginning of the session. Although no stimulus lower than " 20 "' was presented, the subjects were allowed to report estimates lower than " 20 " if they experienced such a sensation (which was common when a mild stimulus immediately followed a very warm stimulus).

In order to compare estimates of the warm sensation produced by conductive heating with the sensation produced by radiant heating, additional sessions were conducted with 4 subjects. A $250-W$ red-bulb infrared lamp was placed $10 \mathrm{~cm}$ behind a $40 \times 40 \mathrm{~cm}$ wooden board with a triangular aperture $(7 \times 14 \mathrm{~cm})$ at the center. Stimulus intensity was controlled with a rheostat, which was calibrated before each session with an Eppley thermopile. At approximately 40-sec intervals, the blindfolded subject was asked to place his or her hand on the aperture, thus exposing $50 \mathrm{~cm}^{2}$ of the palmar surface to the infrared radiation. The stimulus lasted $5 \mathrm{sec}$ and varied from 28 to $600 \mathrm{~mW} / \mathrm{cm}^{2}$ (the approximate warmth and pain thresholds for these subjects were 25 and $700 \mathrm{~mW} / \mathrm{cm}^{2}$, respectively). At the beginning of the session, a $28-\mathrm{mW} / \mathrm{cm}^{2}$ stimulus was presented, and the subject was instructed to call it a " 20 " stimulus. Thirty other stimuli were then presented, by means of the method of constant stimuli.

\section{RESULTS}

All subjects were capable of estimating the magnitude of the thermal stimulus consistently. The scale used by most subjects ranged from about 15 at $33^{\circ} \mathrm{C}$ to 45 at $42^{\circ} \mathrm{C}$, although a few subjects developed very short (14 to 22 ) or very long ( 0 to 115 ) scales. Only 4 subjects gave a response of " 0 ," and the data from the few trials in which this occurred were not considered in data analysis.

The data from each subject were averaged for each integer stimulus temperature, and the resulting means were averaged over all subjects. These grand means are shown in Figure 1. Equations for the relation between mean estimate $(E)$ and stimulus temperature $(T)$ were calculated according to the method of least squares, using the natural data or their logarithms. To facilitate comparisons with data from other experimental situations with different modulus and different threshold levels, sensory magnitude was expressed as a displacement from threshold level $\left(E-E_{0}\right)$, and stimulus magnitude as a displacement from stimulus magnitude at threshold $\left(T-T_{0}\right)$. Under the present experimental conditions, mean $E_{0}$ was 13.4 and mean $T_{0}$ was $33.0^{\circ} \mathrm{C}$. The linear and power functions obtained were $\left(E-E_{0}\right)=-1.29+3.55\left(T-T_{0}\right)$ and $\left(E-E_{0}\right)=2.46\left(T-T_{0}\right)^{1.17}$, respectively. The linear function $(r=0.999)$ was slightly better than the power function $(r=0.998)$.

\section{Intersubject Variability}

Exponents $(\beta)$ and offsets $(k)$ of power functions describing the relationship between sensory estimates and stimulus magnitude were calculated for each experimental session by means of interpolation of logarithms according to the least squares method. Values of $\beta$ and $k$ varied

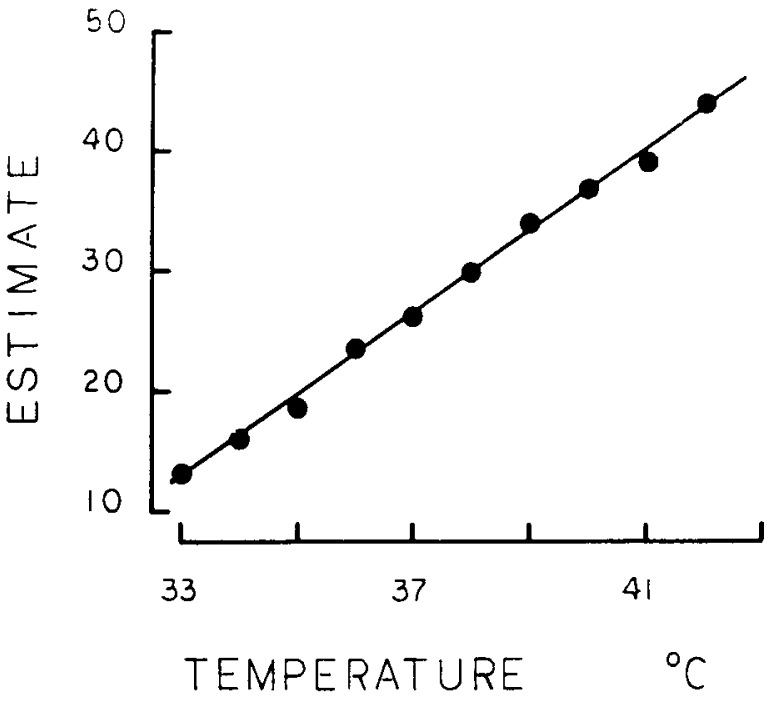

Figure 1. Warmth estimate as a function of stimulus temperature. A standard temperature of $33^{\circ} \mathrm{C}$ was assigned a modulus of "20." Points are overall means: means of the session means for the 52 subjects.

considerably from one subject to another. The mean $\beta$ was 0.74 , with a range from 0.32 to 1.67 . Standard deviation $(S D)$ was $0.30,41 \%$ of the mean. The mean $k$ was 6.10 , with a range from 0.82 to 18.65 . Standard deviation was $4.09,67 \%$ of the mean. There was a significant inverse linear relationship between individual $k \mathrm{~s}$ and $\beta \mathrm{s}$ $(r=-0.459, p<.001)$.

Intersubject variability was not a consequence of gender, age, or body-temperature differences. Thus, mean $\beta$ was not significantly different in males and females $[t(51)=0.750, p>.10]$, and the values of $\beta$ did not correlate well either with age $[r=0.117, p>.10]$ or with sublingual temperature $[r=-0.177, p>.10]$.

\section{Intrasubject Variability}

Only a few subjects were tested repeatedly, which limited the meaningfulness of the results regarding intrasubject variability. An estimate of variability can still be made on the basis of 7 subjects, however. Intrasubject variability was much smaller than intersubject variability. Mean $\beta$ for the 7 subjects tested on three different occasions was 0.72 . Mean intrasubject $S D$ (i.e., $S D$ s of the three sessions' means averaged for the 7 subjects) for $\beta$ was $0.15,21 \%$ of the mean. Mean $k$ was 5.40 . Mean $S D$ for $k$ was $2.05,38 \%$ of the mean. Despite this smaller variability in $\beta$ and $k$ in comparison with intersubject data, the correlation coefficient for the values of $\beta$ between two sessions of a same subject was only $r=0.594, p>.10$. The coefficient for the values of $k$ was also low and not significant: $r=0.497, p>.10$.

\section{Conductive versus Radiant Heating}

The values of $\beta$ obtained with infrared heating were a little lower than those obtained with conductive heating. Mean $\beta$ for the 4 subjects in the radiant-heating condi- 
tion was 0.54 , as compared to 0.74 in the conductiveheating condition. Again, the linear interpolation was slightly better than the power function $\left(r_{\text {lin }}=0.95\right.$, $\left.r_{\text {pow }}=0.90\right)$. Figure $2(\mathrm{~A}$ and $\mathrm{B})$ shows the estimates of a subject in the two conditions. By means of attaching an extra thermocouple (nominal time constant $=5 \mathrm{msec}$ ) to the palmar surface of the subject's hand, it was possible to measure skin surface temperature during stimulation. Part $\mathrm{C}$ in Figure 2 shows that conductive and radiant heating produce similar functions at low values of skin temperature, but that the curve for conductive heating is a little steeper.

\section{DISCUSSION}

Previous studies on magnitude estimation of warmth have established that sensory magnitude is a power func-
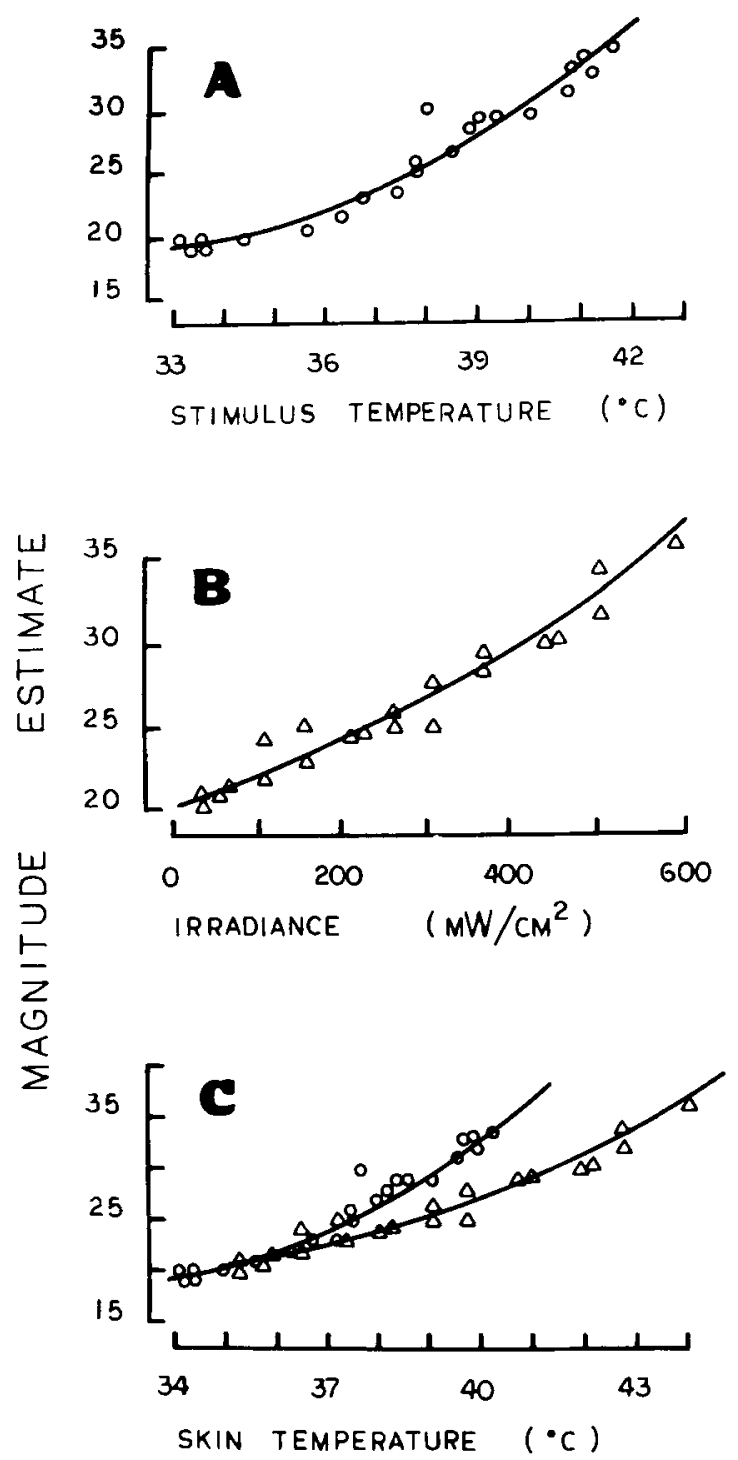

Figure 2. Warmth estimates from the same subject during conductive heating (A) and radiant heating (B) of the palmar surface. The same data are replotted in $\mathrm{C}$ as a function of skin temperature. tion of stimulus magnitude. There has been little agreement, however, about the value of the exponent $\beta$ for a given stimulus location and stimulus size. For instance, exponents for $2-\mathrm{sec}$ warm stimulation of $22 \mathrm{~cm}^{2}$ of skin on the forehead have ranged from 0.76 (J. C. Stevens \& Marks, 1971) to 1.10 (Marks \& J. C. Stevens, 1973b). The mean data in the present study (Figure 1) show a linear relationship between sensory magnitude and stimulus magnitude $(r=0.999)$. Because a power-function relationship is only a little less evident $(r=0.998)$, and because of the ample applicability of the power function to other sensory modalities (S. S. Stevens, 1970; R. Teghtsoonian, 1971), one could argue in favor of the power function. The most parsimonious choice is probably to adopt the linear equation and call it a power function, with $\beta=1.0$.

Discussions of the exact mathematical function that connects warmth sensation with stimulus temperature have minor significance, however, because of the high variability among different subjects. The curve bends to the right for some subjects $(\beta>1)$ and to the left for others $(0<\beta<1)$, so that the behavior of only a few individual subjects is actually described by the straight line (or power function with $\beta=1$ ) that describes mean performance (Figure 1). The values of $\beta$ varied from 0.32 to 1.67 . The values of the constant $k$, whose variability was most likely reduced by the common reference (" 20 ") provided by the experimenter, were also rather variable.

Intersubject variability was twice as large as intrasubject variability. The intersubject standard deviation of $\beta$ was $41 \%$ of the mean, whereas the intrasubject $S D$ was $21 \%$ of the mean. As was the case with the warmth threshold (Gray, J. C. Stevens, \& Marks, 1982), however, intersubject variability could not be accounted for by gender or age differences. Body temperature also did not correlate significantly with $\beta$. In addition, conductive heating and radiant heating produced similar effects at low intensities, as has been shown for the warmth threshold (Kenshalo, Decker, \& Hamilton, 1967), but their effects seemed to differ at higher intensities.

Most studies on the variability of $\beta$ have found larger inter- than intrasubject variability (Da Silva \& Fukusima, 1986; Engeland \& Dawson, 1974; Hellman, 1981; Logue, 1976). In some cases, however, it has been shown that low intrasubject variability is a methodological artifact resulting from practice and learning (M. Teghtsoonian \& R. Teghtsoonian, 1971, 1983). The present experiment does not help solve the problem, since intrasubject variability was found to be half as large as intersubject variability but individual $\beta$ s did not correlate significantly between different sessions.

In short, it seems that, within a session, individual subjects are very consistent in their estimates of warmth, but that the amount of intersubject variability precludes the determination of a single mathematical equation that would apply to all members of the species. All we can say is that the estimates have a general linear trend. The high intersubject variability could not be ascribed to gender, age, or body-temperature differences. Also, stimulus size, 
stimulus duration, stimulus location, and state of adaptation were all controlled to a reasonable extent and therefore could not account for the results obtained. Whether the low intrasubject variability is due to perceptual constancy, to response-strategy constancy, or to practice and learning remains to be determined.

\section{REFERENCES}

Da Silva, J. A., \& Fukusima, S. S. (1986). Stability of individual psychophysical functions for perceived distance in natural indoor and outdoor settings. Perceptual \& Motor Skills, 63, 891-902.

Ekman, G., Hosman, B., Lindman, R., LJUngberg, L., \& Ákesson, C. A. (1968). Interindividual differences in scaling performance. Perceptual \& Motor Skills, 26, 815-823.

ENGEland, W., \& Dawson, W. E. (1974). Individual differences in power functions for a 1-week intersession interval. Perception \& Psychophysics, 15, 349-352.

Graham, C. H. (1950). Behavior, perception and the psychophysical methods. Psychological Review, 57, 108-120.

Gray, L., Stevens, J. C., \& Marks, L. E. (1982). Thermal stimulus thresholds: Sources of variability. Physiology \& Behavior, 29, 355-360.

Hellman, R. P. (1981). Stability of individual loudness functions obtained by magnitude estimation and production. Perception \& Psychophysics, 29, 63-70.

HENSEL, H. (1981). Thermoreception and temperature regulation. London: Academic Press.

Herget, C. M., Granath, L. P., \& Hardy, J. D. (1941). Thermal sensation and discrimination in relation to intensity of stimulus. American Journal of Physiology, 134, 645-655.

Jones, F. N., \& Marcus, M. J. (1961). The subject effect in judgments of subjective magnitude. Journal of Experimental Psychology, 61, 40-44.

JoNES, F. N., \& Woskow, M. H. (1962). On the relationship between estimates of magnitude of loudness and pitch. American Journal of Psychology, 75, 669-671.

Kenshalo, D. R., Decker, T., \& Hamilton, A. (1967). Spatial summation on the forehead, forearm, and back produced by radiant and conducted heat. Joumal of Comparative \& Physiological Psychology, $63,510-515$.

Kenshalo, D. R., Scott, H. A., JR. (1966). Temporal course of thermal adaptation. Science, 151, 1095-1096.

LoGUE, A. W. (1976). Individual differences in magnitude estimation of loudness. Perception \& Psychophysics, 19, 279-280.

MARKs, L. E., \& STEVENS, J. C. (1973a). Spatial summation of warmth:
Influence of duration and configuration of the stimulus. American Journal of Psychology, 86, 251-267.

MARKs, L. E., \& STEvens, J. C. (1973b). Temporal summation related to the nature of the proximal stimulus for the warmth sense. Perception \& Psychophysics, 14, 570-576.

Marks, L. E., Stevens, J. C., \& TePper, S. J. (1976). Interaction of spatial and temporal summation in the warmth sense. Sensory Processes, 1, 87-98.

MolinarI, H. H., Greenspan, J. D., \& Kenshalo, D. R. (1977). The effects of rate of temperature change and adapting temperature on thermal sensitivity. Sensory Processes, 1, 354-362.

RULE, S. J. (1966). Subject differences in exponents of psychophysical power functions. Perceptual \& Motor Skills, 23, 1125-1126.

Rule, S. J., \& MARKLEY, R. P. (1971). Subject differences in crossmodality matching. Perception \& Psychophysics, 9, 115-117.

STEVENS, J. C. (1983). Thermal sensation: Infrared and microwaves. In E. R. Adair (Ed.), Microwaves and thermoregulation (pp. 191201). New York: Academic Press.

STEvens, J. C., \& MARKs, L. E. (1967). Apparent warmth as a function of thermal irradiation. Perception \& Psychophysics, 2, 613-619.

STEVens, J. C., MARKs, L. E. (1971). Spatial summation and the dynamics of warmth sensation. Perception \& Psychophysics, 9, 391-398.

Stevens, J. C., Marks, L. E., \& Simonson, D. C. (1974). Regional sensitivity and spatial summation in the warmth sense. Physiology \& Behavior, 13, 825-836.

Stevens, J. C., Stevens, S. S. (1960). Warmth and cold: Dynamics of sensory intensity. Joumal of Experimental Psychology, 60, 183-192.

STEvens, S. S. (1966). Matching functions between loudness and ten other continua. Perception \& Psychophysics, 1, 5-8.

SteVENS, S. S. (1970). Neural events and the psychophysical law. Science, 170, 1043-1050.

Teghtsoonian, M., \& Teghtsoonian, R. (1971). How repeatable are Stevens's power law exponents for individual subjects? Perception \& Psychophysics, 10, 147-149.

Teghtsoonian, M., \& Teghtsoonian, R. (1983). Consistency of individual exponents in cross-modal matching. Perception \& Psychophysics, 33, 203-214.

Teghtsoonian, R. (1971). On the exponents in Stevens's law and the constant in Ekman's law. Psychological Review, 78, 71-80.

Teghtsoonian, R., \& Teghrsoonian, M. (1978). Range and regression effects in magnitude scaling. Perception \& Psychophysics, 24, 305-314.

(Manuscript received December 2, 1987; revision accepted for publication December 16, 1988.) 